\title{
Surfactant protein A and other bronchoalveolar lavage fluid proteins are altered in cystic fibrosis
}

\author{
C. von Bredow*, P. Birrer", M. Griese*
}

\begin{abstract}
Surfactant protein $A$ and other bronchoalveolar lavage fluid proteins are altered in cystic fibrosis. C. von Bredow, P. Birrer, M. Griese. (C) ERS Journals Ltd 2001. ABSTRACT: Inflammation and proteolytic processes play an important role in the progression of cystic fibrosis (CF) lung disease. The goal of this study was to describe bronchoalveolar lavage fluid (BALF) protein pattern of CF patients in comparison to controls and to assess if there is proteolytic degradation of surfactant protein A (SP-A), an important innate host defence component of the lungs.

BALFs from 17 clinically stable CF patients and from eight healthy children were separated by two-dimensional gel electrophoresis. Silver staining was used to show BALF proteins and Western blotting to detect SP-A isoforms.

In CF, BALF proteins of a low molecular weight $\leqslant 20 \mathrm{kD}$ were more abundant than in controls. Various proteins were seen in $\mathrm{CF}$ which were not present in controls and vice versa. Degradation of SP-A was present in 15 of 17 CF BALFs but in none of the controls, in contrast polymeric isoforms were seen in all controls and in four of $17 \mathrm{CF}$ patients.

Proteolytic damage to surfactant protein $A$ and significant changes of normal bronchoalveolar lavage fluid proteins occur in lungs of cystic fibrosis patients. Identification of altered bronchoalveolar lavage fluid proteins may give new insights into pathogenic mechanisms and provide new targets for therapy.

Eur Respir J 2001: 17: 716-722.
\end{abstract}

*Children's Clinic of Ludwig-Maximilians-University, Munich, Germany. ${ }^{\#}$ Children's Clinic, Inselspital, University of Bern, Switzerland.

Correspondence: M. Griese, Kinderklinik und Kinderpoliklinik im Dr. von Haunerschen Kinderspital, LudwigMaximilians University, Pettenkoferstrasse 8a, Munich, Germany, D-80336 Fax: 498951603477

Keywords: Bronchoalveolar lavage, cystic fibrosis, proteome, surfactant protein $\mathrm{A}$

Received: August 302000

Accepted after revision December 8 2000

This project was supported by a grant from the Wilhelm Sander Stiftung $(\mathrm{Gr}$ 93.002.1/2)
Cystic fibrosis (CF) is a lethal hereditary disorder caused by mutations of the $\mathrm{CF}$ transmembrane conductance regulator (CFTR) gene leading to abnormal exocrine gland secretion and chronic inflammation of the airways. A massive influx of activated neutrophils and high levels of proteolytic enzymes play a major role in the progression of CF lung disease and occur early in life [1-3]. The airway of CF patients is susceptible to infection with various organisms, most notably Pseudomonas aeruginosa, Staphylococcus aureus and Haemophilis influenzae.

Bronchoalveolar lavage fluid (BALF) proteins are a potential source for detecting and characterizing biochemical alterations associated with airway diseases. In healthy subjects BALF proteins were predominantly identified as serum proteins $[4,5]$. Alterations of nasal fluid or BALF proteome (the set of proteins expressed in a specific compartment) have so far been reported for a limited number of respiratory diseases not including CF [5-8]. In this study the differences between the BALF proteome of CF patients compared to controls were analysed. In addition the hydrophilic surfactant associated protein A (SP-A), which plays a central role in host defence in the air space [9] was focused on. In vivo studies confirmed the important role of SP-A in the innate immune system of the lung by demonstrating an increased susceptibility to P. aeruginosa and Group B Streptococci in SP-A knock out mice [10]. Human SP-A is a glycoprotein composed of 18 polypeptide chains, each of about $34 \mathrm{kD}$ molecular weight, isoelectric point 4.2-4.9. SP-A interacts with a variety of bacteria, viruses and fungi including $\mathrm{CF}$ associated pathogens as $P$. aeruginosa, $S$. aureus, $H$. influenza [9] and Aspergillus fumigatus [11] and enhances the uptake of some of these organisms by phagocytic cells [12]. Adequate amounts of functional SP-A must be present in the lung to maintain host defence. In previous studies altered BALF concentrations of SP-A in CF have been demonstrated $[13,14]$. Based on in vitro studies $[15,16]$, it is likely that degradation of SP-A may occur in vivo in $\mathrm{CF}$ and this may contribute to impaired host defence in $\mathrm{CF}$.

Alterations of the BALF proteome and of SP-A are presented in $17 \mathrm{CF}$ patients compared to eight healthy children using high-resolution two-dimensional polyacrylamid gel electrophoresis (2D-PAGE).

\section{Materials and methods}

\section{Patient population}

BALF was obtained from eight healthy children and 17 patients with CF. The healthy subjects had no history of chronic respiratory disease or upper and lower tract infections in the 2-month period prior to 
Table 1. - Clinical characteristics of cystic fibrosis patients and healthy controls

\begin{tabular}{lccc}
\hline & Control & CF & p-value \\
\hline Subjects n & 8 & 17 & \\
Age yrs & $9.5 \pm 1.7$ & $14.9 \pm 1.0$ & 0.01 \\
FEV1 \% & Not measured & $77.2 \pm 7.1$ & \\
Total cells & $10.2 \pm 1.2$ & $307 \pm 68$ & 0.014 \\
$\times 10^{4} \cdot \mathrm{mL}^{-1}$ BALF & & & \\
Neutrophils \% & $0.7 \pm 0.3$ & $60.8 \pm 6.4$ & $<0.0001$ \\
Lymphocytes \% & $15.1 \pm 5.5$ & $5.8 \pm 1.1$ & 0.027 \\
Macrophages \% & $84.1 \pm 5.5$ & $32.8 \pm 5.9$ & $<0.0001$ \\
Eosinophils \% & $0.1 \pm 0.1$ & $0.5 \pm 0.2$ & NS \\
Bacteriology & No growth & $\begin{array}{c}\text { P. aeruginosa } 9 \\
\text { H. influenza } 1\end{array}$ \\
& & No growth 7 & \\
\hline
\end{tabular}

Results are expressed as the mean \pm SEM for $\mathrm{n}$ independent determinations. Comparisons were made for continuous variables by an unpaired two-tailed t-test. FEV1: forced expiratory volume in one second; BALF: bronchoalveolar lavage fluid; $\mathrm{CF}$ : cystic fibrosis.

participation in this study. These children were undergoing elective surgery for nonpulmonary diseases. After written informed consent, BAL was performed under general anaesthesia and tracheal intubation before surgery.

The 17 patients with $\mathrm{CF}$ were in a clinically stable condition and had no changes in therapy for $>2$ weeks. They were randomly selected from the CF outpatient department (table 1). The diagnosis was established by typical clinical manifestation of the disease and confirmed by positive sweat tests in all CF patients. In the genetic analysis six of the $17 \mathrm{CF}$ patients were homozygous for $\Delta \mathrm{F} 508$, eight heterozygous and three showed other infrequent mutations. At the time of evaluation none of the subjects had an acute exacerbation of the lung disease. The BAL procedure was carried out under local anaesthesia. The study protocol was approved by the institutional review boards and written informed consent was obtained from the parents of all children and of older children before the study.

\section{Bronchoalveolar lavage}

BAL was performed in the right middle lobe with a flexible bronchoscope using $3 \mathrm{~mL} \cdot \mathrm{kg}^{-1}$ of $0.9 \% \mathrm{NaCl}$ as previously described in detail [13]. For further analysis BALF was filtered through one layer of loose, sterile gauze and centrifuged at $200 \times g$ for $10 \mathrm{~min}$ at $4^{\circ} \mathrm{C}$ immediately after BAL. To avoid ex vivo degradation of proteins, aliquots of BALF supernatant were immediately frozen at $-70^{\circ} \mathrm{C}$ until assayed. The cell differential was evaluated using cytospin preparations of BALF and bacteriology was evaluated with standard techniques.

\section{Determination of neutrophil elastase activity}

Neutrophil elastase (NE) activity was determined spectrophotometrically using the specific substrate $N$ -
Suc-Ala-Ala-Ala-p-Nitroanilide (Elastin Products Co., Owensville, MO, USA) as described previously [13, 15]. Assays were performed at room temperature on 96 well plates. The change of absorption was measured continuously for $5 \mathrm{~min}$ at $410 \mathrm{~nm}$ in an automated recording spectrophotometer (Anthos HT III, Anthos Labtech Instruments, Salzburg, Austria). NE activity was determined by comparing values obtained from the BALF samples to those of a concurrently run standard (875 U. $\mathrm{mg}^{-1}$, Elastin Products Co., Owensville, MO, USA). All samples were assessed in triplicate.

\section{Two-dimensional electrophoresis}

After the addition of Pefabloc protease inhibitor (Merck, Darmstadt, Germany), lavage fluid aliquots were desalted by extensive dialysis at $4{ }^{\circ} \mathrm{C}$ (tubing cutoff $1 \mathrm{kD}$ ). Protein content was assessed before lyophilization and samples containing $80 \mu \mathrm{g}$ of total protein were separated by horizontal high-resolution two-dimensional electrophoresis under reducing and denaturing conditions according to GöRG [17]. In preliminary experiments a high reproducibility for the location and abundance of the protein-spots on the gel was shown. Gels were silver stained [18] or proteins were transferred onto nitrocellulose membranes (Amersham Pharmacia Biotech, Uppsala, Sweden) for semi-dry Western blotting. SP-A was identified with a specific polyclonal antibody to human SP-A (1:5000; Byk Gulden, Konstanz, Germany). Purified human SP-A isolated from patients with pulmonary alveolar proteinosis served as a standard. Clara cell protein (rabbit anti-human urine protein 1$)$, albumin and $\alpha_{1}$-protease inhibitor $\left(\alpha_{1}-\mathrm{PI}\right)$ were also identified with specific antibodies (Dako, Glostrup, Denmark). Enhanced chemiluminescence assay (Amersham Life Science, Amersham, Buckinghamshire, UK) with horseradish-peroxidase-conjugated goat antirabbit polyclonal immunoglobulin (Ig)-G (1:10,000; BioRad, Hercules, CA, USA) as a second antibody was used for detection.

Silver-stained gels and blots were scanned with a computing densitometer (Fluor-S MultiImager, Melanie 2.1 software (BioRad, Richmond, CA, USA)). To find corresponding protein-spots between gels, all silver-stained gels of each group ( $\mathrm{CF}$ and control) were stacked and spots were matched according to molecular weight, isoelectric point standards and 15 hand-selected landmarks being present in each gel. Two "synthetic gels" were created with Melanie 2.1 software, one for CF and one for controls. These gels contained only the characteristic protein-spots for each group which have been detected in $\geqslant 85 \%$ of all gels in each group [19]. These synthetic gels were matched to gels of the other group (e.g. CF versus control) to identify differences in protein-spot patterns. Direct quantification of proteins in silver-stained gels or Western blot analysis were performed by measuring the relative volume $(\mathrm{Vol} \%)$ of the spots. The $\mathrm{Vol} \%$ was calculated by dividing the Vol of a single spot through the sum of the Vol of all spots of a gel times 100 . The Vol of a spot is defined as $\sum \mathrm{I}(\mathrm{x}, \mathrm{y})$, where I $(\mathrm{x}, \mathrm{y})$ is defined as the intensity of a point $\mathrm{p}(\mathrm{x}, \mathrm{y})$ being part of the spot. I $(\mathrm{x}, \mathrm{y})$ is calculated by the software 
dependent on the saturation of the spot with respect to silver staining properties [19].

\section{Statistical analysis}

Results are expressed as the mean \pm SEM for $\mathrm{n}$ independent determinations. Comparisons for continuous variables were made by an unpaired two-tailed t-test or for frequencies by the Chi-squared test, correlation analysis was performed by calculating the Pearson correlation coefficient.

\section{Results}

The total and differential cell counts of the BALF in $\mathrm{CF}$ differed significantly from control BALF (table 1) showing a well-known neutrophil-dominated inflammation $[1,3]$. In the cell free BALF supernatant free $\mathrm{NE}$ was present in 14 of $17 \mathrm{CF}$ patients but in none of the controls $\left(\mathrm{CF} 10.4 \pm 2.8 \mathrm{U} \cdot \mathrm{mL}^{-1}\right)$. The elastase activity was correlated with the neutrophil cell count in BALFs $(r=0.6 ; p=0.014)$. Total protein content was elevated in $\mathrm{BALF}$ of $\mathrm{CF}$ compared to controls $(\mathrm{CF}$ $314 \pm 46 \mu \mathrm{g} \cdot \mathrm{mL}^{-1}$; control $105 \pm 32 \mu \mathrm{g} \cdot \mathrm{mL}^{-1} ; \mathrm{p}=0.007$ ) and was correlated with the total cell count $(\mathrm{r}=0.75$; $\mathrm{p}=0.0006)$, the neutrophil cell count $(\mathrm{r}=0.77 ; \mathrm{p}=0.0006)$, and the NE activity in BALF $(r=0.71 ; p=0.0014)$.

\section{Bronchoalveolar lavage proteome}

The BALF proteins of all CF patients and controls were separated by 2D-PAGE and silver-stained. The protein display of CF BALF showed major differences from that of controls (table 2, fig. 1). In control subjects albumin was the most abundant single protein $(26.3 \pm 3 \%$ as estimated in $\mathrm{Vol} \%$ of total silver-stained proteins) in BALF. Western blot analysis with antibodies against human serum albumin showed, that albumin was infrequently present in CF BALF. No proteolytic fragments of albumin were found. In contrast in CF BALF $\alpha_{1}$-PI was the most predominant protein $\left(9.3 \pm 1.9 \mathrm{Vol}^{1} \%\right)$ but was uncommonly seen in controls (table 2, fig. 1). The $\mathrm{Vol} \%$ of $\alpha_{1}$-PI has been found to correlate with the activity of $\mathrm{NE}\left(\mathrm{U} \cdot \mathrm{mL}^{-1}\right)$ in BALF $(\mathrm{r}=0.75 ; \mathrm{p}<0.0005)$. Low molecular weight (LMW) proteins were more abundant on silver-stained gels in CF than in controls (fig. 1). Therefore, two groups of proteins with respect to high $(>20 \mathrm{kD})$ or low $(\leqslant 20 \mathrm{kD})$ molecular weight were arbitrarily created in each gel. In CF BALF, LMW protein-spots of $\leqslant 20 \mathrm{kD}$ represented $>40 \%$ of visible spots and nearly $50 \%$ of total protein (as estimated in $\mathrm{Vol} \%$ of total silverstained proteins) being 3-7-fold elevated compared to control BALFs (table 2; fig. 1). There was a positive correlation between the $\mathrm{Vol} \%$ of $\mathrm{LMW}$ proteins $\leqslant 20$ $\mathrm{kD}$ and the neutrophil cell count in BALF $(\mathrm{r}=0.6$; $\mathrm{p}=0.015$ ). There was no significant correlation noted to $\mathrm{NE}$ activity, forced expiratory volume in one second (FEV1), the age at BAL or total protein content. CF patients showing a positive bacterial culture of BALF $(n=10)$ had significantly more spots in the LMW $\leqslant 20$ $\mathrm{kD}$ than those without bacteriological findings (43.2 \pm $2.1 \%$ versus $35.3 \pm 2.8 \%$ of total number of spots on gel; $\mathrm{p}=0.025$ ).

Some proteins were seen in CF BALF, but not in those of controls and vice versa. To localize these proteins on the gels the Melanie 2.1 software package (Biorad, Richmond, CA, USA) was used [19]. Two synthetic gels were created (fig. 2), one for controls containing all spots being present in $\geqslant 7$ of 8 control gels (67 spots) and one for $\mathrm{CF}$, containing those protein spots being present in $\geqslant 15$ of 17 of $\mathrm{CF}$ gels (76 spots). Afterwards, these two resulting synthetic gels were matched to all native silver-stained gels of the other group. Nineteen protein spots were unique for the CF group, 14 of these being located in the LMW $\leqslant 20 \mathrm{kD}$ (fig. 2). In contrast, 14 protein spots of the high molecular weight range were present in $\geqslant 7$ of 8 of the control gels, but in none of CF gels (fig. 2).

\section{Analysis of surfactant protein $A$}

Although the amount of SP-A in BALF did not vary significantly between $\mathrm{CF}$ and controls, remarkable qualitative changes for SP-A were found. Enriched SPA, which is associated with the 40,000 g BALF pellet was separated by $2 \mathrm{D}-\mathrm{PAGE}$ under reducing conditions on immobilized pH gradient (IPG) strips pH 4-5.5. Silver staining of these gels showed a characteristic chain of 16-18 single protein-spots with a molecular

Table 2. - Analysis of silver-stained proteins separated by high-resolution two-dimensional polyacrylamid gel electrophoresis (2D-PAGE)

\begin{tabular}{lrrr}
\hline & Control & CF & p-value \\
\hline Subjects n & \multicolumn{1}{c}{17} \\
Total number of proteins in $80 \mu \mathrm{g}^{*}$ & $190 \pm 63$ & $189 \pm 50$ & 0.977 \\
Number of proteins with MW $\leqslant 20 \mathrm{kD}$ of total protein $\%{ }^{*}$ & $14.5 \pm 3.9$ & $40.3 \pm 7.8$ & $<0.0001$ \\
Vol $\%$ of proteins with MW $\leqslant 20 \mathrm{kD}$ of total protein* $^{*}$ Vol $\alpha_{1}$-protease inhibitor of total protein & $7.7 \pm 1.1$ & $49.0 \pm 2.6$ & $<0.0001$ \\
Vol $\%$ of albumin of total protein $^{+}$ & $0.5 \pm 0.2$ & $9.3 \pm 1.9$ & 0.0051 \\
\hline
\end{tabular}

Results are expressed as the mean \pm SEM for $\mathrm{n}$ independent determinations. Comparisons were made for continuous variables by an unpaired two-tailed t-test. *: these data result from the analysis of silver-stained 2D PAGE gels by Melanie 2.1 software. $\mathrm{Vol} \%$ of a given protein spot is a function of its area and its intensity referred to the volume of all protein spots on the gel. +: proteins were identified by Western blot analysis of bronchoalveolar lavage proteins after separation by two dimensional electrophoresis under reducing conditions. Corresponding protein spots were localized on silver-stained gels run in parallel. Analysis was performed as described above for the silver-stained gels. 
a)

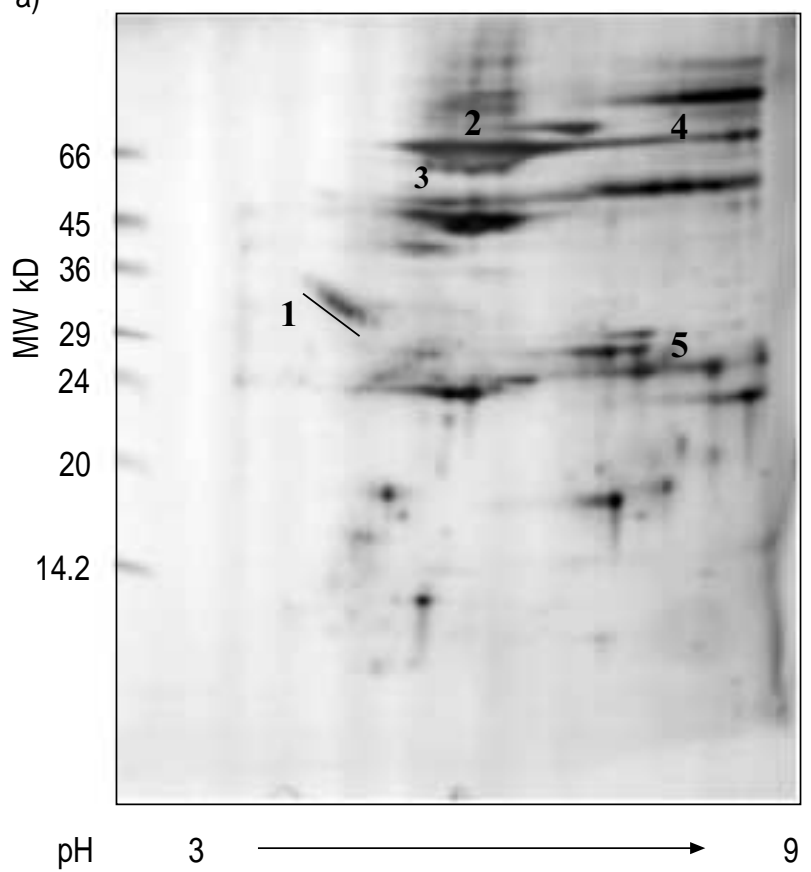

b)

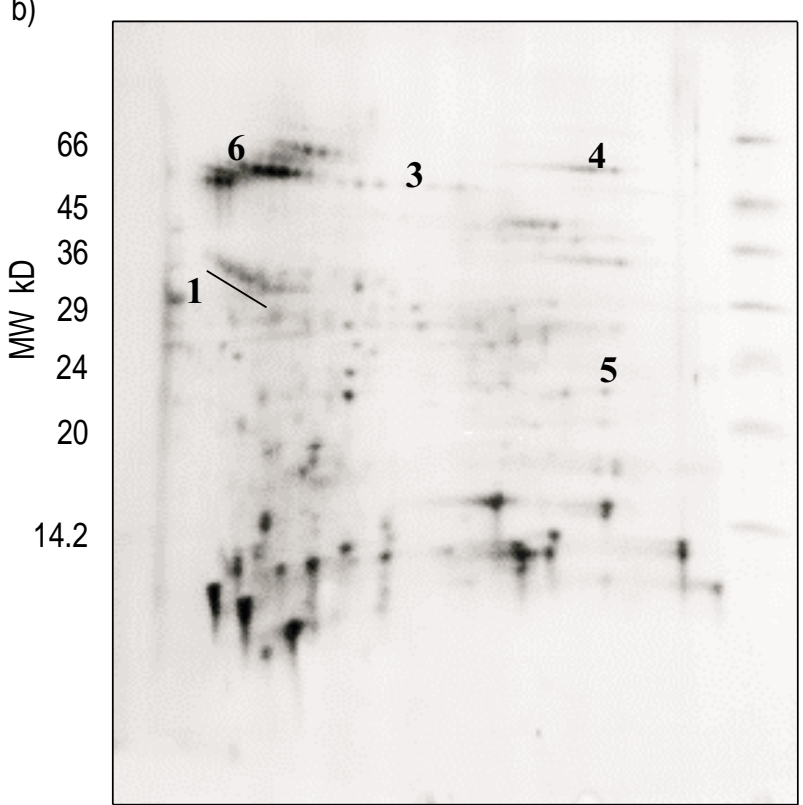

$\mathrm{pH} \quad 3$

Fig. 1. - Representative high-resolution two-dimensional polyacrylamid gel electrophoresis (2D-PAGE) pattern of bronchoalveolar lavage fluid (BALF) proteins of a) a healthy child and b) a cystic fibrosis (CF) patient showing moderate human neutrophil elastase activity $\left(3.9 \mathrm{U} \cdot \mathrm{mL}^{-1}\right)$. Separated proteins were detected by silver staining. The 2 D-PAGE was performed under reducing conditions on a linear immobilized $\mathrm{pH}$ gradient $\mathrm{pH} 3-10$, followed by a $12 \%$ SDS-PAGE. The figure contains scanned gels, presented as an unmanipulated image, except for overall contrast using programs for graphic processing. Identified proteins are indicated with numbers. 1: surfactant protein A*; 2: albumin*; 3: immunglobulin A $\alpha$ chain*; 4 : immunglobulin $\mathrm{G}$ heavy chain*; 5 : immunglobulin $\mathrm{G}$ light chains $\mathrm{k}, \lambda^{*} ; 6: \alpha 1-\mathrm{PI}^{+}$. Proteins were identified by *: comparison with a master plasma pattern in Swiss-2D PAGE database; ${ }^{+}$: western immunoblotting. a)

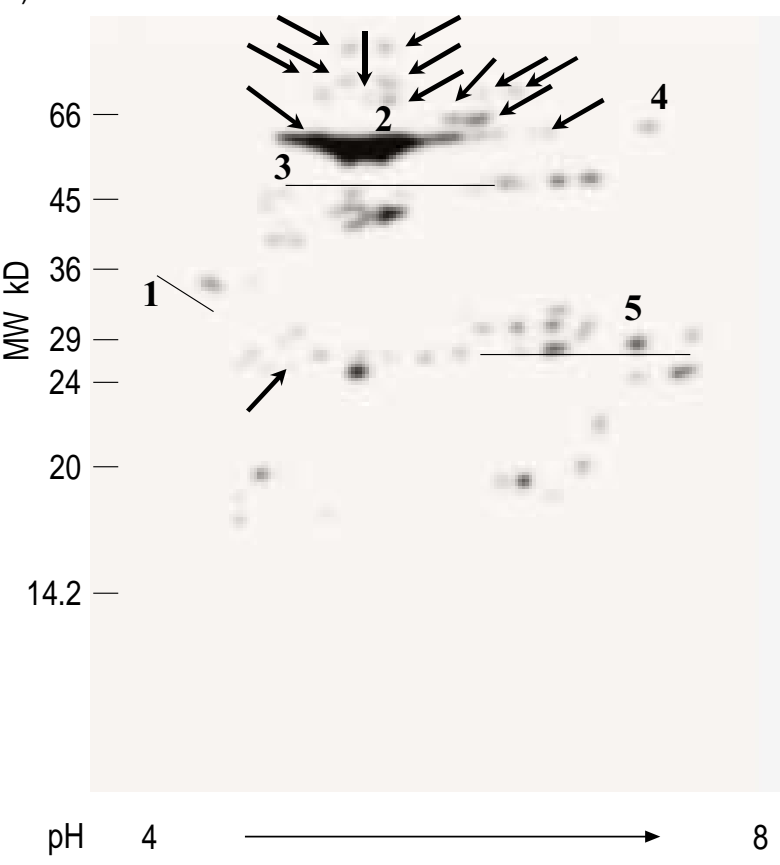

b)

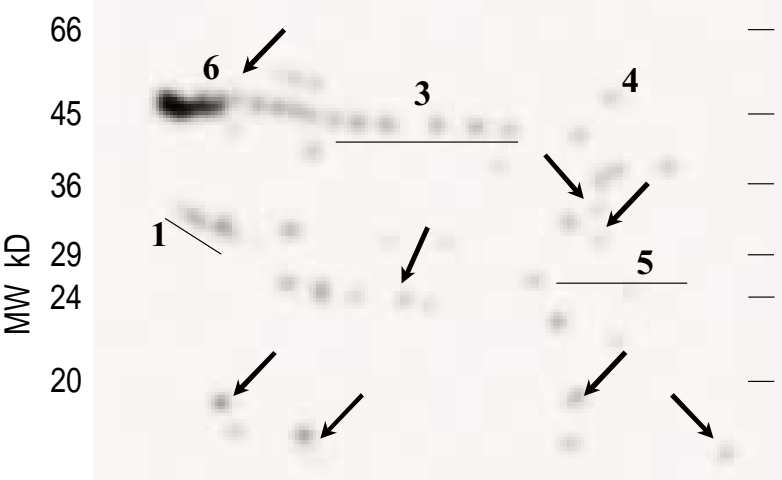

14.2

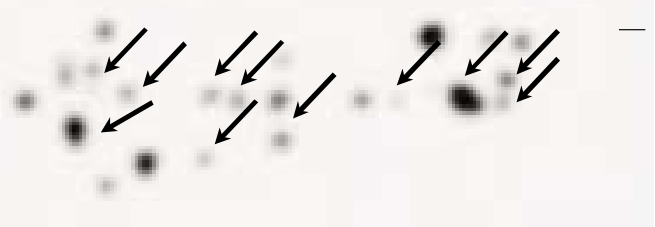

$\mathrm{pH} \quad 4$

8

Fig. 2. - Two synthetic 2D-gels created by Melanie 2.1 software containing only characteristic protein spots for each group: a) cystic fibrosis (CF) and b) control. Scanned, silver-stained gels of each bronchoalveolar lavage fluid (BALF) were analysed by the software and spots being present in $\geqslant 7$ of 8 control gels were copied in the control synthetic gel, spots being present in $\geqslant 15$ of 17 of CF gel were copied in the CF synthetic gel. Each of the two resulting synthetic gels were matched to all silver-stained gels of the other group to find protein spots being characteristic for the one group and not being present in the other group. Unique characteristic protein spot, for which no corresponding protein spot can be found in gels of the other group, indicated by arrows. 1: surfactant protein A; 2: albumin ; 3 : immunglobulin A $\alpha$ chain ; 4: immunglobulin $\mathrm{G}$ heavy chain; 5 : immunglobulin $\mathrm{G}$ light chains $\mathrm{k}, \lambda ; 6: \alpha_{1}-\mathrm{PI}$. 

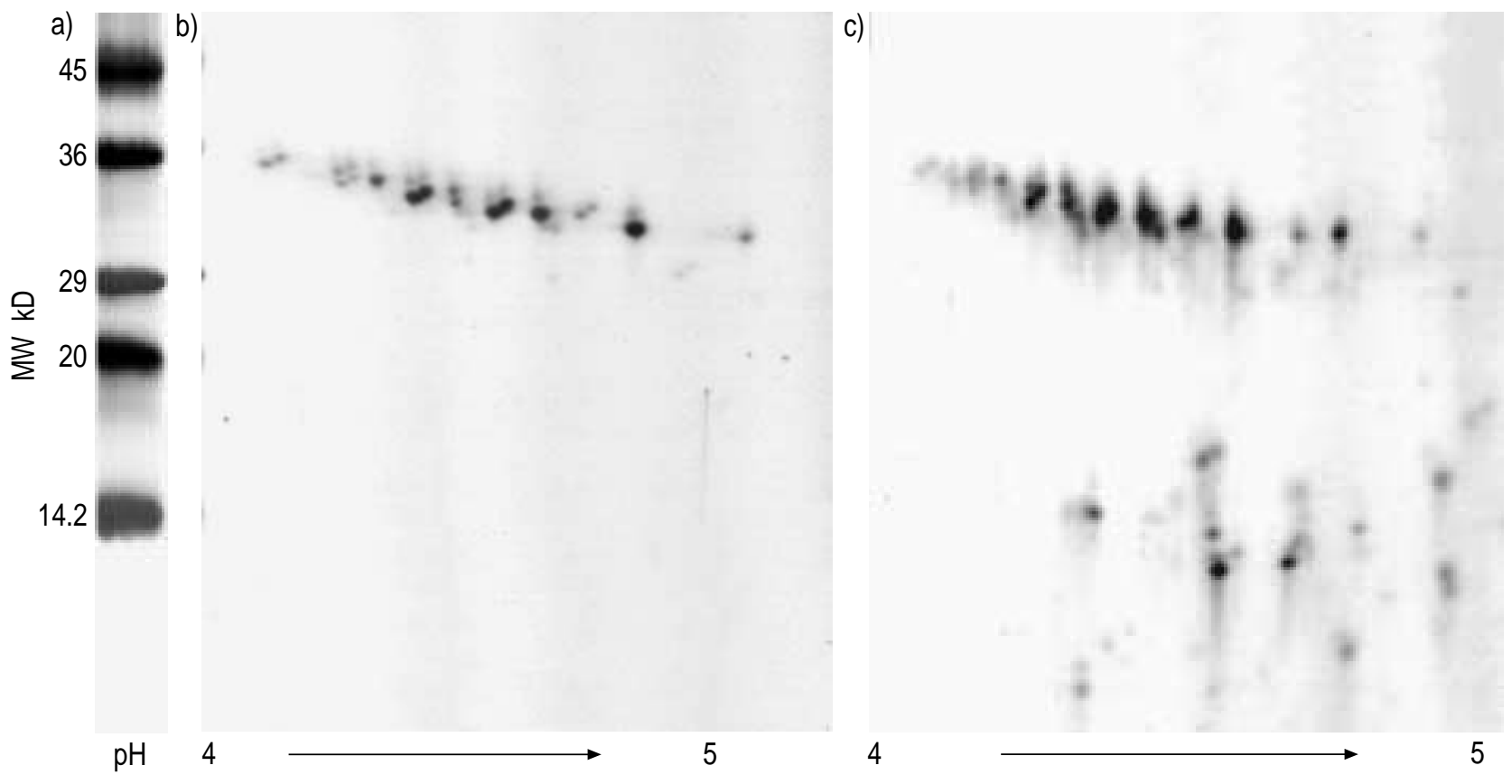

Fig. 3. - a) Molecular weight standard; b) surfactant protein A (SP-A) of a healthy child; c) SP-A of a cystic fibrosis (CF) patient. SP-A associated to the pellet of bronchoalveolar lavage fluid (BALF) after $40,000 \times g$ centrifugation was separated under reducing conditions by high-resolution two-dimensional polyacrylamide gel electrophoresis (2D-PAGE) (linear immobolized $\mathrm{pH}$ gradient $\mathrm{pH} 4-5.5$ ) and detected by silver staining. The presence of SP-A was confirmed by Western blotting with polyclonal antibodies raised against human SP-A on an equal gel run in parallel.

weight of $31-35 \mathrm{kD}$ and isoelectric points of $4.2-4.9$ in both the $\mathrm{CF}(\mathrm{n}=3)$ and control $(\mathrm{n}=2)$ groups (fig. 3$)$. In $\mathrm{CF}$ additional protein-spots with a molecular weight of $\sim 14-24 \mathrm{kD}$ and $\mathrm{pH}$ of $4.5-5.1$ were noted. 2D-PAGE gels of the same samples of BALF run in parallel were subjected to Western blotting and it was demonstrated, that these LMW protein-spots were immunoreactive with a polyclonal antibody to SP-A, as were the higher MW protein spots. Systematic Western blot analysis of all native BALF supernatants on IPG pH 3-10 demonstrated that LMW degradation products were present in 15 of $17 \mathrm{CF}$ patients in varying quantity, but in none of the eight controls (table 3, fig. 4). In contrast, polymeric forms of SP-A were observed in all controls but in only four of $17 \mathrm{CF}$ patients. These polymers of SP-A comprised of a molecular weight from $\sim 60 \mathrm{kD}$ up to $>100 \mathrm{kD}$ and could not be reduced despite addition of increasing amounts of reducing agents (data not shown). The Vol\% of SP-A degradation products correlated to the number of total cells in BALF $(r=0.5$; $\mathrm{p}=0.045)$, but not significantly to NE activity or neutrophil cell count. CF patients showing a positive bacterial culture of BALF $(n=10)$ had more degradation of SP-A than those without bacteriological findings, not reaching significance $(16.2 \pm 4.3$ versus $7.4 \pm$ $2.3 \mathrm{Vol} \%$ of total SP-A; $\mathrm{p}=0.13)$.

\section{Discussion}

In this study it has been shown, that significant differences in the overall BALF protein-patterns and qualitative alterations of SP-A in CF adolescents with clinical stable disease compared to healthy controls exist. Besides an elevated content of total protein, the BALF protein-pattern of CF patients differed significantly to that of controls, the latter showing a wellknown concordance to the proteome of human serum [4-7].

In $\mathrm{CF}$ BAL and sputum a variety of proteases are elevated and are likely to play a role in the progression of the lung disease. Among these NE is one of the most

Table 3. - Analysis of surfactant protein A (SP-A) by high-resolution two-dimensional polyacrylamid gel electrophoresis

\begin{tabular}{lccr}
\hline & Control & CF & p-value \\
\hline Subjects n & 8 & 17 & \\
Vol\% monomeric SP-A of total SP-A* & $77.9 \pm 13.3$ & $86.0 \pm 12.2$ & 0.096 \\
Number of BALFs with polymeric SP-A & 8 & 4 & 0.012 \\
Vol\% polymeric SP-A of total SP-A* & $19.7 \pm 3.3$ & $0.8 \pm 0.5$ & $<0.0001$ \\
Number of BALFs with degradated SP-A & 0 & 15 & 0.0014 \\
Vol\% degradated SP-A of total SP-A* & 0 & $13.2 \pm 2.8$ & $<0.0001$ \\
\hline
\end{tabular}

Results are expressed as the mean \pm SEM for $\mathrm{n}$ independent determinations. Comparisons were made for continuous variables by an unpaired two-tailed t-test. *: Vol\% considering intensity and area of each spot on blot referred to the volume of total visible SP-A. BALFs: bronchoalveolar lavage fluids. 

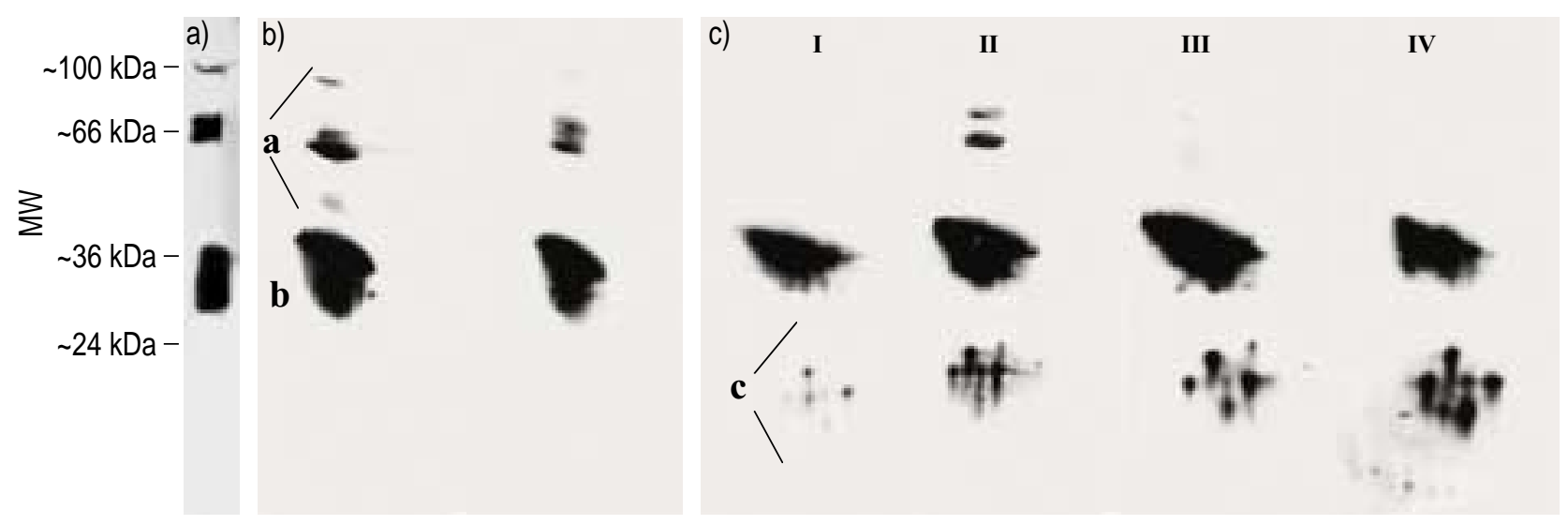

Fig. 4. - Immunochemical staining patterns of surfactant protein A (SP-A) in bronchoalveolar lavage fluid (BALF) separated by (2DPAGE), immobolized $\mathrm{pH}$ gradient $\mathrm{pH}$ 3-10 linear. Nitrocellulose blots were probed with polyclonal antibodies raised against human SP-A, chemiluminescence was used for detection. a) One dimensional separated isolated human SP-A as a standard; b) two dimensional separated SP-A of BALF proteins from two representative control subjects; c) two dimensional separated SP-A from four representative patients with CF showing different human leukocyte elastase (HLE) activities in BALF; I: patient with $0.9 \mathrm{U} \cdot \mathrm{mL}^{-1} \mathrm{HLE}$ activity; II: patient with $3.5 \mathrm{U} \cdot \mathrm{mL}^{-1} \mathrm{HLE}$ activity; III: patient with $3.9 \mathrm{U} \cdot \mathrm{mL}^{-1} \mathrm{HLE}$ activity; IV: patient with $18.6 \mathrm{U} \cdot \mathrm{mL}^{-1} \mathrm{HLE}$ activity; a: Diand polymeric forms of SP-A, MW $\sim 66-100 \mathrm{kD}$; b: monomeric form of SP-A $\sim 30-36 \mathrm{kD}$, pI 4.2-4.9; c: degradation products of SP-A MW $\sim 14-24 \mathrm{kD}$.

abundant active neutrophil proteases. Thus in this study the findings were correlated to the activity of NE in BALF as a common representative of neutrophil derived proteolytic enzymes.

To better describe the proteome alterations in BALF, two different groups of proteins according to low $(\leqslant 20$ $\mathrm{kD})$ and high $(>20 \mathrm{kD})$ molecular weight were arbitrarily created. The predominance of the LMW $(\leqslant 20$ $\mathrm{kD})$ proteins in CF BALF may at least partly be due to an accumulation of degraded structure, defence, bacterial or inflammatory proteins. This is in accordance with the data of a previous report by the authors, where an 8 week inhalation of $\alpha_{1}$-PI in CF patients led to a significant reduction in the number and $\mathrm{Vol} \%$ of these LMW proteins $\leqslant 20 \mathrm{kD}$ [20]. Various proteins were seen in $\mathrm{CF}$, which were not present in controls and vice versa. These proteins need to be identified in future studies as they allow a quantification of the relative abundance of various components involved in the inflammatory and proteolytic processes in CF lung disease. The primary goal of this study was to establish the overall protein pattern in $\mathrm{CF}$ and to localize potential targets for sequencing and protein identification.

In accordance with previous reports of elevated $\alpha_{1}$-PI levels in CF sputum the $\mathrm{Vol} \%$ of $\alpha_{1}$-PI of total protein was much higher in CF BALF than in controls [3, 21]. As the $\mathrm{Vol} \%$ of $\alpha_{1}$-PI was strongly correlated to the $\mathrm{NE}$ activity in BALF, $\alpha_{1}$-PI must have been inactivated by proteolysis or oxidation [3, 21]. The latter clearly predominated, as no degradation products of $\alpha_{1}$-PI were found by Western blot analysis (data not shown).

In addition to the altered protein-pattern of $\mathrm{CF}$ BALF qualitative changes for SP-A were found. SP-A was degraded to LMW products in the majority of BALFs of CF patients. Higher molecular forms were not present in CF BALF but were in all the controls. High resolution 2D-PAGE was used to describe in detail the human SP-A isomers of BALF of control and $\mathrm{CF}$ patients. The molecular weight and $\mathrm{pI}$ of the main chain of SP-A isomers are not altered in CF and are also in accordance with reports in the literature [22, 23]. BAKER et al. [24] and DOYLE et al. [25] previously described the qualitative impairment of SP-A in BALF of patients with acute respiratory distress syndrome [25] and of patients with pulmonary alveolar proteinosis [25] compared to controls. Both found alterations in the distribution between polymeric and isomeric forms of SP-A, but no LMW products of SP-A (MW <24 kD). As confirmed by Western blotting, these proteolytic fragments of SP-A with a molecular weight of $\sim 14$ $24 \mathrm{kD}$ were present in the majority of $\mathrm{CF}$ patients but in none of the controls. As there is a correlation of Vol $\%$ SP-A degradation products to the total number of cells in BALF, SP-A is likely to be damaged by cellrelated proteolytic enzymes as NE or other proteases as Cathepsin $\mathrm{G}$ or $\mathrm{B}$ and collagenases. In vitro studies suggest, that rat and dog SP-A can be cleaved by NE $[13,14]$ and collagenase [26] resulting in proteolytic fragments of $21 \mathrm{kD}(\mathrm{NE})$ or $20-23 \mathrm{kD}$ and $\mathrm{pI}$ of $4.2-$ 4.8 (collagenase). In these studies the biophysical function of surfactant in surface adsorption was impaired after exposure to the above proteases. Thus it is likely that the impaired biophysical function of surfactant in $\mathrm{CF}$ may in part be related to proteolytic damaged SP-A. Loss of the host defence properties with impaired SP-A is likely, but has to be demonstrated in future studies.

The high molecular assemblies $(>60 \mathrm{kD})$ of SP-A were found in all BALFs from controls but almost not in CF. These forms of SP-A were likely to represent dimers and oligomers [25], but it is not known how they are generated and what their exact functional role is. A quantitative reduction of SP-A in BALF from CF patients with severe lung disease has been reported previously $[13,14]$, whereas in asymptomatic CF infants no alterations and with infection an upregulation of SP-A has been noted [27]. Reduction of SP-A with advanced disease may be due to a reduced synthesis or excessive proteolytic degradation of SP-A. In the latter case the generated fragments must be small enough not 
to be detected by specific antibodies in enzyme linked immunosorbent assay (ELISA). The proteolytic fragments of $14-24 \mathrm{kD}$ observed in this study will still be reactive in ELISA tests using the same antibodies as in Western blot. Therefore, the total amount of intact SP-A will be overestimated in ELISA.

Interestingly elevated LMW proteins, SP-A fragments and NE activity have been observed in the absence of bacterial or fungal findings in CF BALF. This indicates that inflammation and subsequent damage of lung proteins can occur independent of bacterial findings in $\mathrm{CF}$ lung.

It is concluded, that proteolytic damage of surfactant protein-A and the changes of other bronchoalveolar lavage fluid proteins are likely to be due to a neutrophil dominated inflammation and might contribute to a reduced ability in cystic fibrosis to remove the specific pathogens from their lungs. After the identification and characterization of the proteins expressed under various clinical conditions, therapeutic interventions aimed at reducing the inflammation and the proteolytic activity in the airspace may be monitored by the changes in the proteome display.

\section{References}

1. Konstan MW, Hilliard KA, Norvell TM, Berger M. Bronchoalveolar lavage findings in cystic fibrosis patients with stable, clinically mild lung disease suggest ongoing infection and inflammation. Am J Respir Crit Care Med 1995; 150: 448-454.

2. Khan TZ, Wagner JS, Bost T, Martinez J, Accuso FJ, Riches DW. Early pulmonary inflammation in infants with cystic fibrosis. Am J Respir Crit Care Med 1995; 151: 1075-1082.

3. Birrer P, Mvelvaney G, Rüdelberg A, et al. Proteaseantiprotease imbalance in the lungs of children with cystic fibrosis. Am J Respir Crit Care Med 1994; 151: 207-213.

4. Golaz O, Hughes GJ, Frutiger S, et al. Plasma and red blood cell protein maps: update 1993. Electrophoresis 1993; 14: 1223-1231.

5. Wattiez R, Hermans C, Bernard A, Lesur O, Falmagne P. Human bronchoalveolar lavage fluid: two dimensional gel electrophoresis, amino acid microsequencing and identification of major proteins. Electrophoresis 1999; 20: 1634-1640.

6. Lindahl M, Stahlbom B, Tagesson C. Newly identified proteins in human nasal and bronchoalveolar lavage fluids: potential biochemical and clinical applications. Electrophoresis 1999; 20: 3670-3676.

7. Lindahl M, Stahlbom B, Svartz J, Tagesson C. Protein patterns of human nasal and bronchoalveolar lavage fluids analysed with two dimensional gel electrophoresis. Electrophoresis 1998; 19: 3222-3229.

8. Lenz AG, Meyer B, Costabel U, Maier K. Bronchoalveolar lavage proteins in human lung disease: analysis by two-dimensional electrophoresis. Electrophoresis 1993; 14: 242-244.

9. Haagsmann HP. Interactions of surfactant protein A with pathogens. Biochemica et Biophysica Acta 1998; 1408: 264-277.

10. Korfhagen TR, LeVine AM, Whitsett A. Surfactant protein A (SP-A) gene targeted mice. Biochemica et Biophysica Acta 1998; 1408: 296-302.
11. Madan T, Eggleton P, Kishore U, et al. Binding of pulmonary surfactant protein $\mathrm{A}$ and $\mathrm{D}$ to Aspergillus fumigatus conidia enhance phagocytosis and killing by human neutrophils and alveolar macrophages. Infect Immun 1997; 65: 3171-3179.

12. Pikaar JC, Voorhut WF, van Golde LM, Verhoef J, van Stijp JA, van Iwaarden JF. Opsonic activities of surfactant protein A and D in phagocytosis of gram negative bacterial by alveolar macrophages. $J$ Infect Dis 1995; 172: 481-489.

13. Griese M, Birrer P, Demirsoy A. Pulmonary surfactant in cystic fibrosis. Eur Respir J 1997; 10: 19831988.

14. Postle AD, Mander A, Reid KBM, et al. Deficient hydrophilic lung surfactant proteins $\mathrm{A}$ and $\mathrm{D}$ with normal surfactant phospholipid molecular species in cystic fibrosis. Am J Respir Cell Mol Biol 1999; 20: 90 98.

15. Pison U, Tam EK, Caughey H, Hawgood S. Proteolytic inactivation of dog lung surfactant-associated proteins by neutrophil elastase. Biochemica et Biophysica Acta 1989; 992: 251-257.

16. Liau DF, Yin NX, Huang J, Ryan SF. Effects of human polymorphonuclear leukocyte elastase upon surfactant in vitro. Biochem Biophys Acta 1996; 1302: 117-128.

17. Görg A, Postel W, Günther S. The current state of two dimensional electrophoresis with immobilized $\mathrm{pH}$ gradients. Electrophoresis 1988; 9: 531-546.

18. Blum H, Beier H, Gross HJ. Improved silver staining of plant proteins, RNA and DNA in polyacrylamid gels. Electrophoresis 1987; 8: 93-99.

19. Appel RD, Vargas RJ, Walther D, Hochstrasser D. Melanie II-a third generation software package for analysis of two-dimensional electrophoresis images. II. Algorithms. Electrophoresis 1997; 18: 2735-2748.

20. Griese M, von Bredow C, Birrer P. Reduced proteolysis of surfactant protein $\mathrm{A}$ and changes of the bronchoalveolar lavage fluid proteom by inhaled $\alpha_{1}$-protease inhibitor in cystic fibrosis. Electrophoresis 2001; 22: 165-171.

21. Goldstein W, Döring G. Lysosomal enzymes from polymorphonuclear leukocytes and proteinase inhibitors in patients with cystic fibrosis. Am Rev Respir Dis 1986; 134: 49-56.

22. Johansson J, Curstedt T, Robertson B. The proteins of the surfactant system. Eur Respir J 1994; 7: 372-391.

23. Phelbs D, Taeusch HW, Benson B, Hawgood S. An electrophoretic and immunochemical characterisation of human surfactant-associated proteins. Biochemica et Biophysica Acta 1984; 791: 226-238.

24. Baker CS, Evans TW, Randle BJ, Haslam P. Damage to surfactant specific protein in acute respiratory distress syndrome. Lancet 1999; 353: 1232-1237.

25. Doyle IR, Davidson KG, Barr HA, Nicholas TE, Payne K, Pfitzner J. Quantity and structure of surfactant proteins vary among patients with alveolar proteinosis. Am J Respir Crit Care Med 1998; 157: 658-664.

26. Whitsett JA, Weaver T, Hull W, Ross G, Dion C. Synthesis of surfactant associated glycoprotein A by rat type II epithelial cells. Primary translation products and post-translational modification. Biochemica et Biophysica Acta 1985; 828: 162-171.

27. Hull J, South M, Phelan P, Grimwood K. Surfactant composition in infants and young children with cystic fibrosis. Am J Respir Crit Care Med 1997; 156: 161165. 